\title{
Pengaruh RAST (Running-Based Anaerobic Sprint Test) terhadap Denyut Jantung dan Kadar Asam Laktat pada Atlet Futsal FIK UNJ
}

\author{
*Bazzar Ari Mighra ${ }^{1)}$, Wahyuningsih Djaali ${ }^{2)}$
}

Program Studi Ilmu Keolahragaan, Fakultas Ilmu Olahraga, Universitas Negeri Jakarta

Corresponden author: bazzar.mighra@gmail.com

Received : 19 Maret $2021 \quad$ Accepted : 29 Maret 2021

Published: 30 Maret 2021

Doi : https://doi.org/10.37012/jik.v13i1.530

\begin{abstract}
- - - - - - - - - - - - - - - -
\section{ABSTRAK}

Asam laktat merupakan produk hasil penggunaan sistem energi anaerobik dan merupakan salah satu faktor yang menentukan kelelahan karena akumulasi asam laktat dalam otot dikaitkan dengan kelelahan otot. Futsal merupakan jenis olahraga yang menggunakan energi secara anaerobik dan aerobik, dan metode RAST (Running-based Anaerobic Sprint Test) adalah salah satu tes untuk mengukur kemampuan daya tahan anaerobik. Penelitian ini bertujuan untuk mengetahui pengaruh RAST terhadap perubahan denyut jantung dan kadar asam laktat yang mengacu pada penggunaan energi anaerobik. Jumlah sampel sebesar 24 orang diikutkan dalam penelitian. Hasil penelitian didapatkan rerat berat badan sebesar $58,33 \mathrm{~kg}$, rerata tinggi badan $168,08 \mathrm{~cm}$, dan rerata IMT 17,73 $\mathrm{kg} / \mathrm{m}^{2}$. Terdapat peningkatan denyut jantung yang bermakna $(\mathrm{p}<0,001)$ pada setelah RAST (rerata $137,29 \pm 18,59 \mathrm{kali} / \mathrm{menit}$ ), dibandingkan sebelum RAST (rerata 74,29 $\pm 10,84 \mathrm{kali} / \mathrm{menit}$ ). Terdapat penurunan kadar asam laktat yang bermakna pada 30 menit setelah RAST (rerata 2,08 $\pm 1,40 \mathrm{mmol} / \mathrm{L}$ ), dibandingkan 5 menit setelah RAST (rerata 6,18 $2,09 \mathrm{mmol} / \mathrm{L}$ ). Hal ini menunjukkan kemampuan pemulihan atlet futsal FIK UNJ setelah melakukan uji RAST tergolong cukup baik.
\end{abstract}

Kata Kunci: Asam laktat, Atlet Futsal, Denyut Jantung, RAST (Running-based Anaerobic Sprint Test).

\begin{abstract}
Lactic acid is a product of the use of the anaerobic energy system and is one of the factors that determine fatigue because the accumulation of lactic acid in muscles is associated with muscle fatigue. Futsal is a type of sport that uses anaerobic and aerobic energy, and the RAST (Runningbased Anaerobic Sprint Test) method is a test to measure anaerobic endurance abilities. This study aims to determine the effect of RAST on changes in heart rate and levels of lactic acid which refers to the use of anaerobic energy. The number of samples of 24 people was included in the study. The results showed that the average body weight was $58.33 \mathrm{~kg}$, the mean height was $168.08 \mathrm{~cm}$, and the average BMI was $17.73 \mathrm{~kg} / \mathrm{m} 2$. There was a significant increase in heart rate ( $p<0.001)$ after RAST (mean 137.29 \pm 18.59 times/minute), compared to before RAST (mean $74.29 \pm 10.84$ times/minute). There was a significant decrease in lactic acid levels at 30 minutes after RAST (mean $2.08 \pm 1.40 \mathrm{mmol}$ / L), compared to 5 minutes after RAST (mean $6.18 \pm 2.09 \mathrm{mmol} / \mathrm{L}$ ). This shows that the recovery ability of FIK UNJ's futsal athletes after carrying out the RAST test is quite good.
\end{abstract}

Keywords: Lactic Acid, Futsal Athletes, Heart Rate, RAST (Running-based Anaerobic Sprint Test). 


\section{PENDAHULUAN}

Dalam olahraga atau latihan fisik berdasarkan pemakaian oksigen atau sistem energi yang dominan digunakan, dapat dibagi menjadi aerobik dan anaerobik. Olahraga aerobik merupakan latihan yang menggunakan energi yang berasal dari penggunaan oksigen, contohnya adalah lari jarak jauh, jalan, bersepeda dll. Olahraga anaerobik merupakan latihan yang menggunakan energi dari pembakaran tanpa menggunakan oksigen dan menimbulkan hutang oksigen.

Terdapat berbagai macam respon yang terjadi setelah latihan fisik, diantaranya adaptasi kardiovaskular, respon imun, serta kelelahan dan nyeri pada otot yang diakibatkan latihan. Salah satu hal yang menyebabkan kelelahan dikarenakan adanya penumpukan asam laktat. Untuk menangani permasalahan kelelahan banyak negara mengembangkan metode yang efektif untuk membantu atletnya agar segera pulih dari kelelahan otot dan untuk membantu para atlet agar mencapai situasi fisiologis yang terbaik. Hal tersebut bertujuan untuk mendapatkan penampilan optimal terutama saat mengikuti kompetisi baik dalam tingkat nasional maupun internasional.

Cabang olahraga futsal merupakan cabang olahraga rutin yang banyak diminati mahasiswa. Olahraga tersebut juga menggunakan energi secara aerob dan anaerob. Penelitian terhadap cabang olahraga yang diminati tersebut akan membantu kemajuan agar cabang-cabang olahraga tersebut dapat memberikan prestasi baik dalam kegiatan nasional maupun internasional. Daya tahan anaerobik sangat diperlukan untuk atlet futsal karena atlet tersebut sering melakukan aktivitas tiba-tiba yang tidak menggunakan oksigen. Apabila atlet kurang memiliki daya tahan anaerobik yang baik, maka atlet tidak dapat melakukan aktivitas dengan intensitas yang maksimal dan durasi yang pendek atau aktivitas yang bersifat eksplosif.

Salah satu tes evaluasi untuk mengetahui kemampuan anaerobik dari atlet adalah uji RAST (Running-based Anaerobic Sprint Test), dan hasil dari penggunaan energi secara anaerobik adalah asam laktat. Pengukuran asam laktat dapat dilakukan setelah uji RAST sehingga mengetahui kadar asam laktat setelah uji RAST dilakukan. Tujuan uji RAST ini dilakukan adalah untuk mengukur kemampuan daya tahan anaerobik (Mackenzie 2005).

Pada studi oleh Neto (2012) yang dilakukan pada 18 orang pemain sepakbola untuk mengevaluasi perubahan kardiovaskular setelah uji RAST, terjadi peningkatan denyut jantung yang signifikan dari $68.9 \pm 12.0 \mathrm{kali} /$ menit menjadi $179.6 \pm 9.1 \mathrm{kali} /$ menit setelah melakukan uji RAST. Selain itu juga terjadi peningkatan tekanan darah sistol yang signifikan dari 118.0 $\pm 11.0 \mathrm{mmHg}$ menjadi $173.0 \pm 25.7 \mathrm{mmHg}$. 
Hasil studi menunjukkan bahwa perubahan kardiovaskular yang terjadi pada uji RAST yang merupakan upaya anaerobik yang mirip dengan perubahan pada upaya aerobik intensitas tinggi.

Tujuan dari penelitian ini adalah ingin melihat bagaimana pengaruh uji RAST terhadap perubahan denyut jantung dan kadar asam laktat atlet futsal Fakultas Ilmu Keolahragaan Universitas Negeri Jakarta (FIK UNJ).

\section{METODE}

Desain penelitian yang dilakukan adalah penelitian analitik obervasional dengan teknik pengambilan sampel "total sampling" pada atlet futsal FIK UNJ. Penelitian dilakukan di FIK UNJ dengan tetap menerapkan protokol kesehatan karena penelitian dilakukan di masa pandemi. Total jumlah sampel yang mengikuti penelitian adalah 24 orang.

Tahapan pengumpulan sampel yaitu dengan meminta persetujuan untuk ikut dalam penelitian, lalu dilakukan anamnesis dan pemeriksaan fisik singkat, dilakukan pengukuran berat badan (BB), tinggi badan (TB), indeks massa tubuh (IMT) dan denyut jantung (heart rate/HR) awal. Subjek kemudian diminta untuk melakukan RAST (Running-based Anaerobic Sprint Test) dan setelah itu dilakukan pengukuran denyut jantung akhir dan kadar asam laktat darah. Pengukuran kadar asam laktat darah menggunakan Accutrend Plus Lactate Meter dari Roche.

Analisis data dilakukan dengan menggunakan SPSS. Dilakukan penghitungan rerata dan standar deviasi masing-masing variabel yang diukur, dan dilakukan pengujian statistik perubahan denyut jantung pada sebelum dan setelah melakukan RAST dengan uji perbedaan rerata “uji T berpasangan”. Kemaknaan hasil uji dinilai dengan nilai p<0,05.

\section{HASIL DAN PEMBAHASAN}

Karakteristik dasar subjek penelitian ditunjukkan pada tabel di bawah berdasarkan beberapa variabel, yaitu umur, berat badan, tinggi badan, indeks massa tubuh (IMT) dari subjek penelitian. Deskripsi data disajikan dalam bentuk tabel yang berisi statistik rata-rata (mean) dan standar deviasi (SD).

Tabel 1.

Karakteristik Data Subjek Penelitian

\begin{tabular}{lcc}
\hline \multicolumn{1}{c}{ Karakteristik } & Rerata & SD \\
\hline Umur $($ tahun $)$ & 18,46 & 0,50 \\
Berat badan $(\mathrm{kg})$ & 58,33 & 7,03 \\
Tinggi badan $(\mathrm{cm})$ & 168,08 & 4,42 \\
IMT $\left(\mathrm{kg} / \mathrm{m}^{2}\right)$ & 17,73 & 0,92 \\
\hline
\end{tabular}


Pada tabel 1 terlihat variabel umur, berat badan, tinggi badan dan indeks massa tubuh subjek penelitian. Untuk rata-rata umur sampel yang mengikuti penelitian adalah 18,46 tahun. Sampel yang mengikuti penelitian memiliki rerata berat badan $58,33 \mathrm{~kg}$ dan rerata tinggi badan $168,08 \mathrm{~cm}$, dengan IMT rata-rata $17,73 \mathrm{~kg} / \mathrm{m}^{2}$.

Berdasarkan hasil tersebut, maka atlet futsal FIK UNJ tergolong pada kategori BMI rendah, atau kurang berat badan tingkat ringan. Dari studi oleh Nikolaidis (2019) yang meneliti tentang hubungan antara umur dan IMT dengan ketahanan fisik, dikatakan bahwa mengoptimalkan BMI penting dipertimbangkan sebagai tujuan latihan dan nutrisi untuk meningkatkan kinerja performa olahraga.

Tabel 2.

Denyut jantung (HR) sebelum dan setelah RAST

\begin{tabular}{lccc}
\hline & $\begin{array}{c}\text { HR sebelum RAST } \\
\text { (kali/menit) }\end{array}$ & $\begin{array}{c}\text { HR setelah RAST } \\
\text { (kali/menit) }\end{array}$ & Nilai p \\
\hline Rerata \pm SD & $74,29 \pm 10,84$ & $137,29 \pm 18,59$ & $<0,001^{*}$ \\
Nilai min & 54 & 94 & \\
Nilai maks & 90 & 170 & \\
\hline
\end{tabular}

*Uji T test berpasangan

Pada tabel 2, denyut jantung tertinggi sebelum RAST adalah $90 \mathrm{kali} / \mathrm{menit}$ dengan rerata $74,29 \pm 10,84 \mathrm{kali} / \mathrm{menit}$. Denyut jantung tertinggi setelah RAST adalah $170 \mathrm{kali} / \mathrm{menit}$ dengan rerata $137,29 \pm 18,59 \mathrm{kali} / \mathrm{menit}$. Dari tabel tersebut terlihat bahwa, terdapat peningkatan denyut jantung yang bermakna setelah RAST, dibandingkan sebelum RAST.

Hal ini sesuai dengan teori bahwa pada saat melakukan uji RAST yang merupakan aktivitas berlari dengan kecepatan maksimal, diketahui bahwa saat berlari diperlukan kontribusi dari otot-otot ekstremitas atas dan otot postural dan proporsi otot aktif yang besar, sehingga dibutuhkan pula kebutuhan curah jantung yang lebih besar yang kemudian terjadilah peningkatan denyut jantung. Kemudian, untuk denyut jantung sebelum RAST berada dalam batas normal yaitu di bawah $100 \mathrm{kali} /$ menit, dan untuk batas tertinggi setelah RAST masih di bawah nadi maksimal aktivitas yaitu $170 \mathrm{kali} /$ menit, di mana rumus perhitungan denyut nadi maksimal sesuai umur adalah 220 dikurangi umur. 


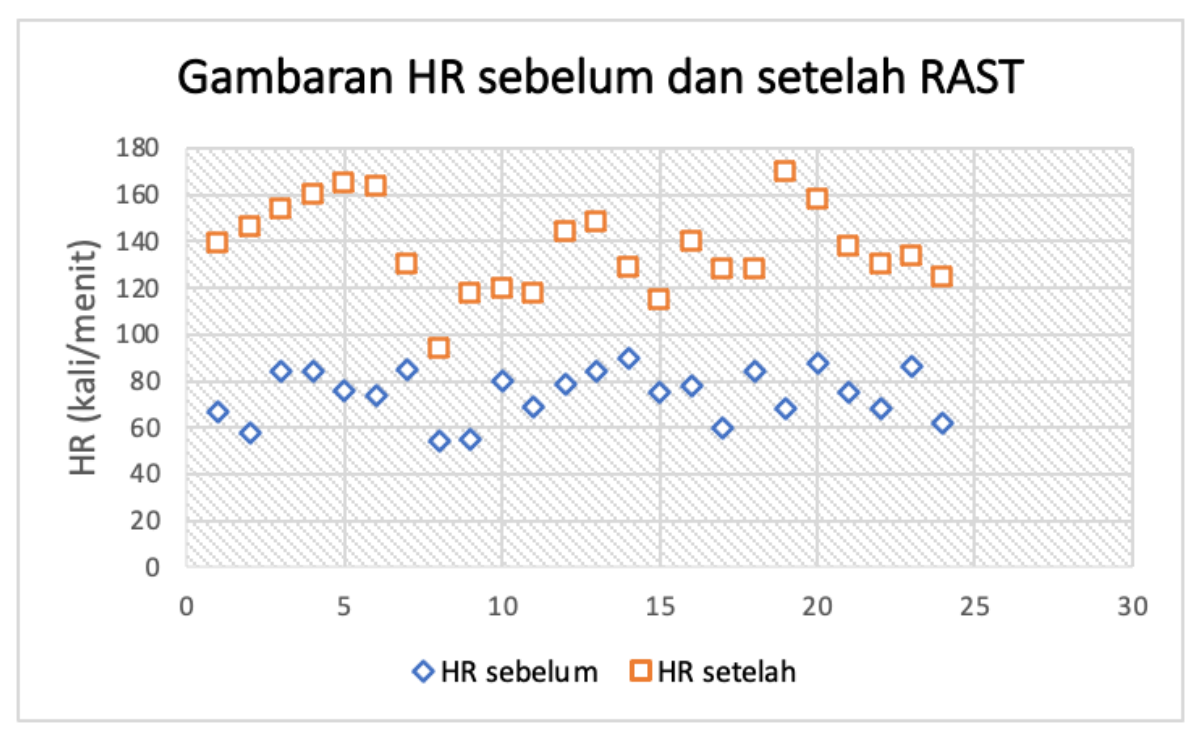

Gambar 1. Gambaran HR pada sebelum dan setelah RAST

Tabel 3.

Kadar asam laktat darah pada 5 menit setelah dan 30 menit setelah RAST

\begin{tabular}{lccc}
\hline & $\begin{array}{c}\text { Asam laktat 5 menit } \\
\text { setelah RAST } \\
(\mathbf{m m o l} / \mathbf{L})\end{array}$ & $\begin{array}{c}\text { Asam laktat 30 menit } \\
\text { setelah RAST } \\
(\mathbf{m m o l} / \mathbf{L})\end{array}$ & Nilai p \\
\hline Rerata \pm SD & $6,18 \pm 2,09$ & $2,08 \pm 1,40$ & \\
Nilai min & 3,3 & 0,1 & $<0,001^{*}$ \\
Nilai maks & 10,9 & 6,2 & \\
\hline
\end{tabular}

*Uji T test berpasangan

Pada tabel 3, kadar asam laktat tertinggi pada 5 menit setelah RAST adalah 10,9 mmol/L dengan rerata $6,18 \pm 2,09 \mathrm{mmol} / \mathrm{L}$. Kadar asam laktat tertinggi pada 30 menit setelah RAST adalah $6,2 \mathrm{mmol} / \mathrm{L}$ dengan rerata $2,08 \pm 1,40 \mathrm{mmol} / \mathrm{L}$. Dari tabel tersebut terlihat bahwa, terdapat penurunan kadar asam laktat yang bermakna pada 30 menit setelah RAST, dibandingkan 5 menit setelah RAST.

Kadar asam laktat darah pada 5 menit setelah RAST memiliki nilai rerata sebesar $6,18 \pm 2,09$ mmol/L dan hal tersebut menunjukkan bahwa hasil tes asam laktat setelah RAST pada atlet futsal FIK UNJ berada di atas ambang laktat yg umum digunakan yaitu 4 mmol/L, sehingga dibutuhkan latihan interval pendek untuk melatih daya tahan anaerobik. Namun, hasil penurunan kadar asam laktat yang bermakna pada menit ke-30 setelah RAST menunjukkan bahwa kemampuan pemulihan setelah melakukan uji RAST cukup baik pada atlet futsal dikarenakan pada menit ke-30 setelah uji RAST kadar asam laktat darah telah kembali ke nilai normal. 


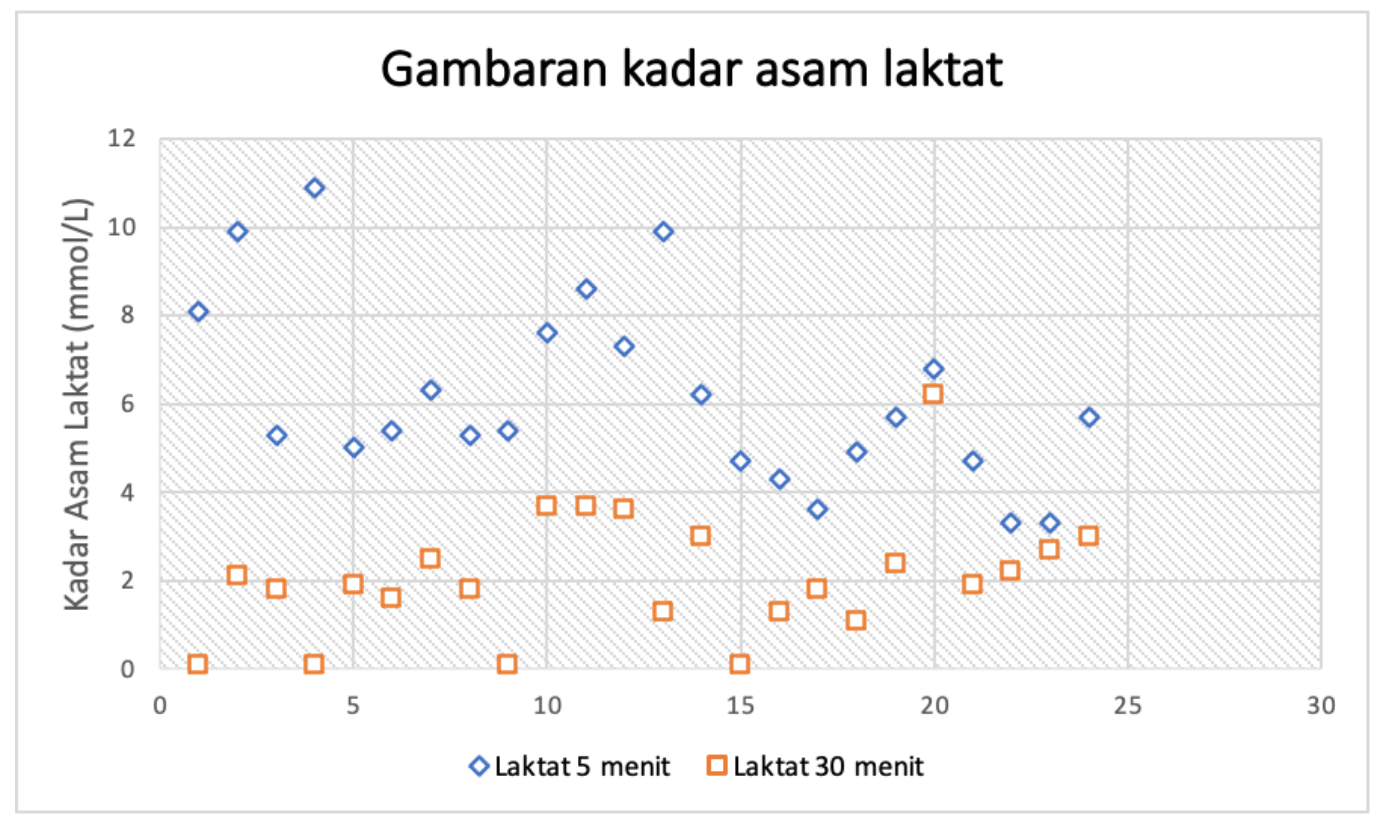

Gambar 2. Kadar asam laktat pada 5 menit setelah dan 30 menit setalah RAST

\section{SIMPULAN DAN REKOMENDASI}

Kesimpulan yang dapat diambil dari penelitian ini adalah terjadi peningkatan denyut jantung yang bermakna setelah uji RAST pada atlet futsal Fakultas Ilmu Keolahragaan Universitas Negeri Jakarta. Selain itu, terjadi penurunan rerata kadar asam laktat darah dari menit ke-5 setelah uji RAST ke menit ke-30. Hal ini menunjukkan kemampuan pemulihan atlet futsal FIK UNJ setelah melakukan uji RAST tergolong cukup baik.

\section{REFERENSI}

1. Brown WM, Davison GW, McClean CM, Murphy MH. A systematic review of the acute effects of exercise on immune and inflammatory indices in untrained adults. Sports medicine-open. 2015;1(1):35.

2. Lin Z-P, Lan LW, He T-Y, Lin S-P, Lin J-G, Jang T-R, et al. Effects of Acupuncture Stimulation on Recovery Ability of Male Elite Basketball Athletes. The American Journal of Chinese Medicine. 2009;37(03):471-81.

3. Mackenzie B. Performance evaluation tests. London: Electric World plc. 2005;24(25):57-158.

4. Neto, J. B., Assumpção, C. D. O., Asano, R. Y., \& Souza, M. A. D. F. (2012). Changes in heart rate and blood pressure in sub-18 soccer players tested with Running-based anaerobic sprint test. In International Journal of Exercise Science: Conference Proceedings (Vol. 1, No. 1, p. 35). 
5. Plowman SA, Smith DL. Exercise physiology for health fitness and performance: Lippincott Williams \& Wilkins; 2013.

6. Sukmaningtyas H, Pudjonarko D. Pengaruh Latihan Aerob1k dan Anaerobik terhadap Sistem Kardiovaskuler dan Kecepatan Reaksi. 2002.

7. Nikolaidis, P. T., Chtourou, H., Torres-Luque, G., Rosemann, T., \& Knechtle, B. (2019). The relationship of age and BMI with physical fitness in futsal players. Sports, 7(4), 87. 